Internal jugular vein cannulation complicated with supraclavicular hematoma and acute upper

S. Mihailovic ${ }^{1}$

\title{
brachial plexopathy
}

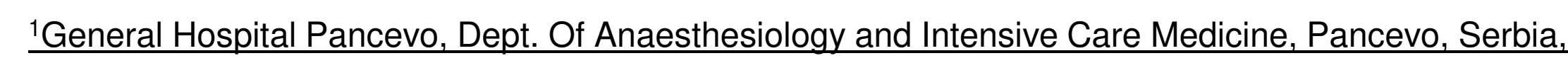

E-mail: stevdr@gmail.com

76-yrs-old chronic HD patient- temporary HD access

I - Landmark Technique - Puncture of Right Carotide Artery

II - US Guidance - Peculiar anatomy revealed !!
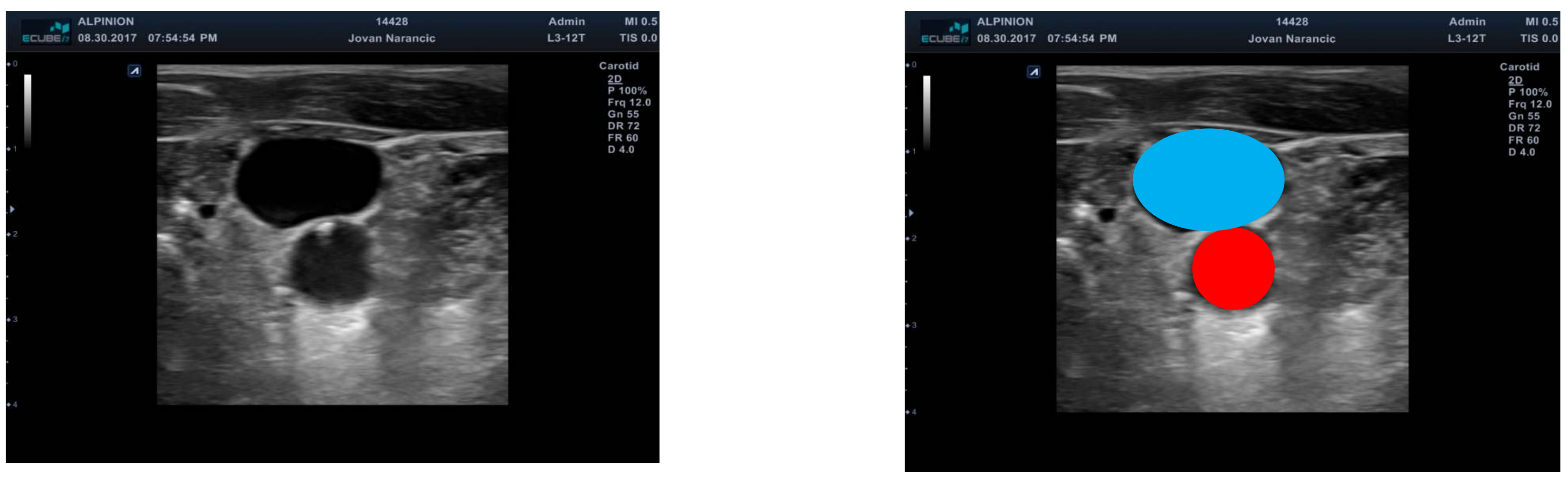

Haemodialisys $4 \mathrm{~h}$ routinly ... $4 \mathrm{hrs}$ after !!!

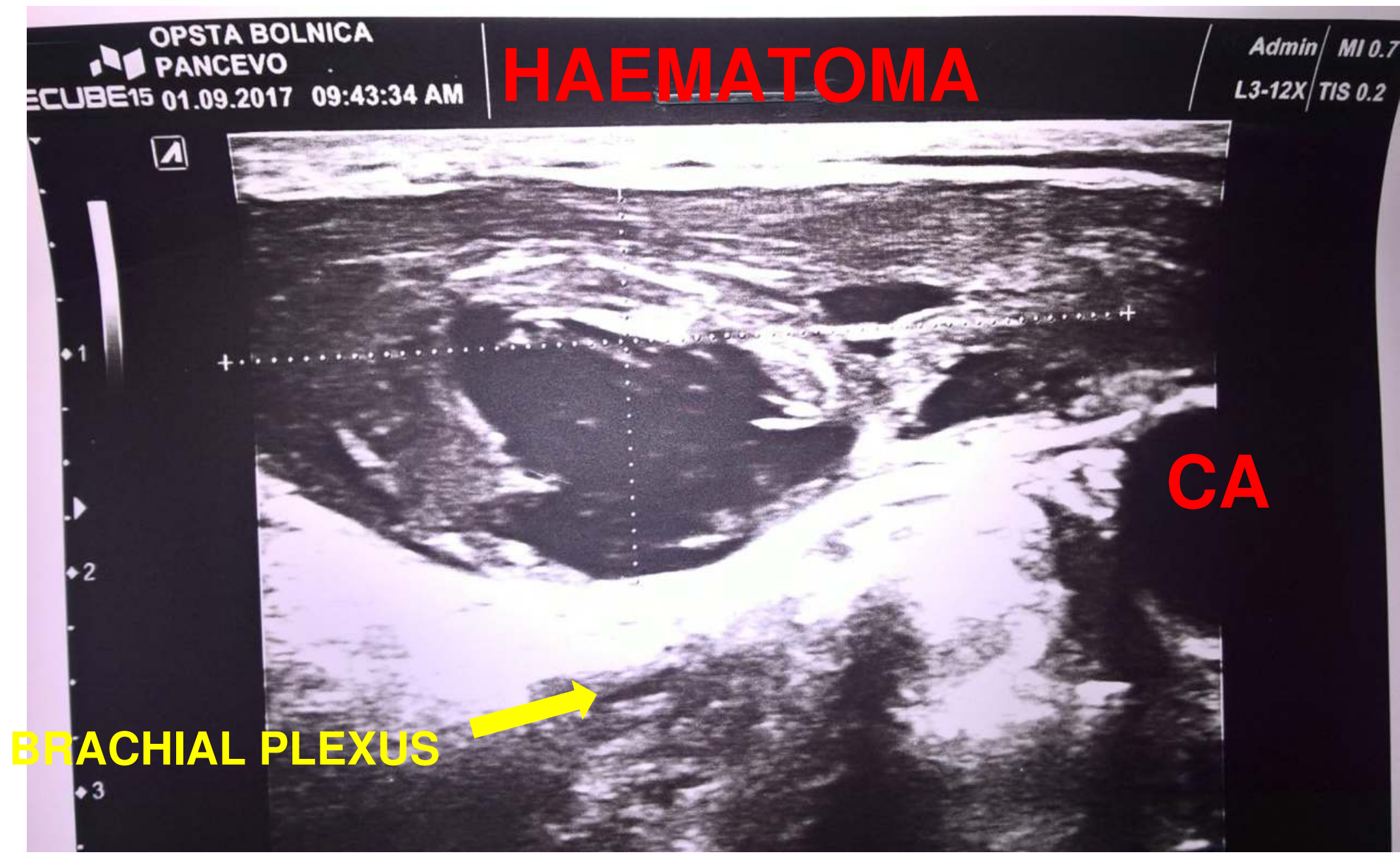

Medical Research Council Manual Muscle Testing

0 No muscle activation
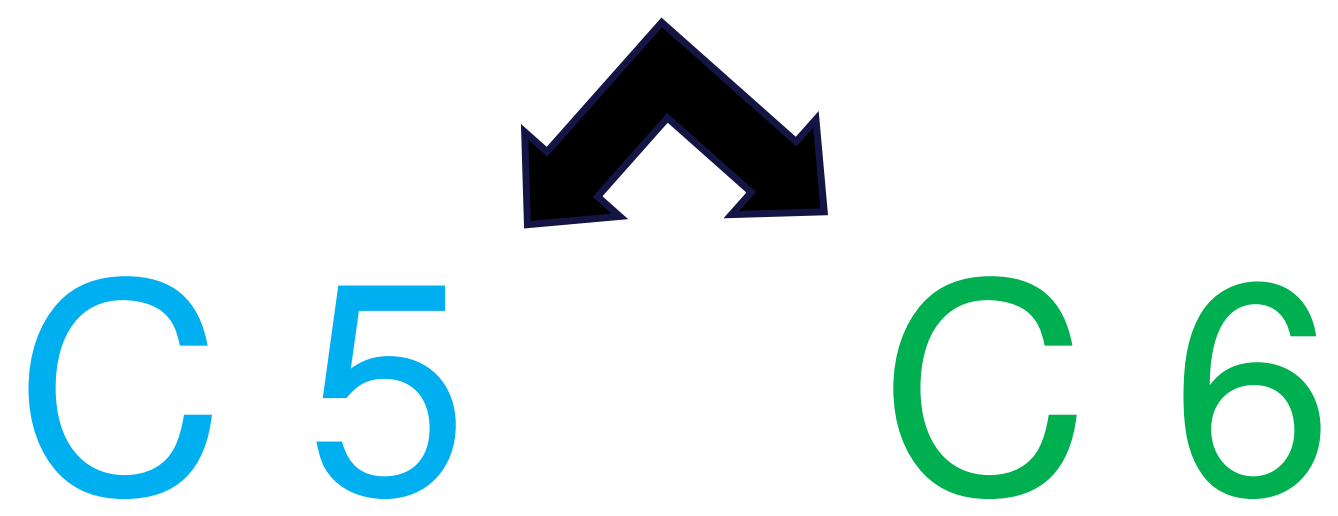

$\underline{\text { Surgeon : Conservative treatment }}-\underline{\text { Cold compression + Dexa + Vitamins I? }}$

Discharged 28 days later - IMPROVED MUSCULAR STRENGHT !

\section{LUCKY OUTCOME - BAD SURGICAL DECISION}

\section{WHY !?}

LOGIC

\& LITERATURE

1. O'Keefe DM. Brachial plexus injury following axillary arteriography: case report and review of the literature. J Neurosurg 1980;53:853-7

2. HJ Kim, SH Park, HY Shin,YS Choi.Korean J Pain.2014.Vol.27.No3:210-218. 